\title{
Toward making inroads in reducing the disparity of lung health in Australian Indigenous and New Zealand Māori children
}

\section{Anne B. Chang 1,2 *, Robyn L. Marsh', John W. Upham ${ }^{3,4}$, Lucas R. Hoffman, ${ }^{5,6}$, Heidi Smith-Vaughan', Deborah Holt ${ }^{1}$, Maree Toombs ${ }^{1,7}$, Catherine Byrnes ${ }^{8}$, Stephanie T. Yerkovich ${ }^{1,4,9}$, Paul J. Torzillo ${ }^{10}$, Kerry-Ann F. O'Grady ${ }^{2}$ and Keith Grimwood ${ }^{11}$ on behalf of the CRE extended group ${ }^{t}$}

${ }^{1}$ Child Health Division, Menzies School of Health Research, Charles Darwin University, Darwin, NT, Australia

2 Queensland Children's Medical Research Institute, Queensland University of Technology, Brisbane, QLD, Australia

${ }^{3}$ Department of Respiratory Medicine, Princess Alexandra Hospital, Brisbane, QLD, Australia

${ }^{4}$ School of Medicine, The University of Queensland, Brisbane, QLD, Australia

${ }^{5}$ Department of Pediatrics, University of Washington, Seattle, WA, USA

${ }^{6}$ Department of Microbiology, University of Washington, Seattle, WA, USA

7 Indigenous Health, Toowoomba Rural Clinical School, The University of Queensland, Toowoomba, QLD, Australia

${ }^{8}$ Paediatric Department, University of Auckland \& Starship Children's Hospital, Auckland, New Zealand

${ }^{9}$ Queensland Lung Transplant Service, The Prince Charles Hospital, Chermside, QLD, Australia

${ }^{10}$ Nganampa Health Council, Alice Springs and Royal Prince Alfred Hospital, The University of Sydney, Sydney, NSW, Australia

"Gold Coast University Hospital, Griffith University, Gold Coast, QLD, Australia

*Correspondence: annechang@ausdoctors.net

${ }^{\dagger}$ CRE extended group (listed below) consists of the grant holders, higher degree research scholars, and collaborators who attended the workshop held at the Queensland Medical Research Institute, Royal Children's Hospital, Brisbane on 24-26 th July 2014.

CRE Chief Investigators: Ngiare Brown, Heather D'Antoine, Amanda Leach, Kim Mulholland, Peter Morris.

CRE Associate Investigators: Bart Currie, Kane Ellis, Bilawara Lee, Barbara Paterson, Rosalyn Singleton.

CRE partners and collaborators who attended the workshop: Helen Buntain, Louise Clark, Allan Cripps, Jan Hammill, lan Mackay, Carolyn Maclennan, Geraint Rogers, Ruth Thornton.

CRE higher degree research scholars: Sophie Anderson-James, Anna Bell, Michael Binks, Ben Drescher, Vikas Goyal, Kerry Hall, Gabrielle McCallum, Linda Medlin, Susan Pizzutto, Jane Pooley, Danielle Wurzel.

CRE post-doctoral current and previous fellows: Kim Hare, Julie Marchant, Elizabeth McDonald, Noritta Morseau-Diop, Helen Petsky.

CRE research team members who attended meeting: Samantha Gardiner, Siew Choo Su, Joanne Tuppin.

Edited by:

Malcolm King, Canadian Institutes of Health Research, Canada

Reviewed by:

Larry C. Lands, Montreal Children's Hospital-McGill University Health Centre, Canada

Hans Pasterkamp, University of Manitoba, Canada

Keywords: Indigenous, acute respiratory infections, outcomes, lung health, bronchiectasis, children

\section{INTRODUCTION}

Globally, Indigenous populations, which include Aboriginal and Torres Strait islanders in Australia and Māori people in New Zealand (NZ), have poorer health than their non-Indigenous counterparts (1). Indigenous peoples worldwide face substantial challenges in poverty, education, employment, housing, and disconnection from ancestral lands (1). While addressing social determinants of health is a priority, solving clinical issues is equally important. Indeed, ignoring the latter until social issues improve risks further disparity as this may take generations. A systematic overview of interventions addressing social determinants of health found a striking lack of reliable evaluations (2). Where evidence was available, health improvement associated with interventions was modest or uncertain (2). Thus, advances in healthcare remain essential and these require the best evidence available in preventing and managing common illnesses, including respiratory illnesses.

\section{THE IMPORTANCE OF RESPIRATORY HEALTH IN CHILDHOOD}

Relative to its substantial disease burden, lung health receives little attention worldwide compared with other conditions, which attract substantially more media attention and support from research funding bodies. Yet, pneumonia remains the most important cause of mortality and morbidity in young children globally $(3,4)$. By 2020 , chronic obstructive pulmonary disease (COPD) is expected to be the third-ranked cause of mortality in the world (5). Moreover, COPD, thought previously to occur only in smokers, is recognized increasingly in non-smoking individuals $(5,6)$. Indeed, those with nonsmoking-related COPD may have poorer clinical outcomes (higher hospitalizations for COPD and pneumonia) than smokingrelated COPD (6). Non-smoking-related COPD is associated with childhood respiratory infections, as is bronchiectasis (7). The latter often goes under-recognized as $29-50 \%$ of people with severe COPD (8), and as many as $40 \%$ of patients with difficult to control asthma and chronic cough, have bronchiectasis (9).

To reduce chronic pulmonary disease in adults, interventions during critical phases of lung development in early childhood and even in the pre and ante-natal periods may be necessary (10-12). Unlike some other organs, the lungs continue to 
develop throughout early childhood (13). Furthermore, pulmonary immunity and respiratory phenotype are influenced by gene-environment interactions early in life (including in utero) (14). If lung function is already decreased in infancy, this can persist (track) throughout childhood and predict future respiratory morbidity (15). Indeed, there is increasing evidence that much adult lung disease [such as COPD (6) and bronchiectasis] originates in childhood (where it is potentially preventable) $(16,17)$.

There are few published Australian data on the changes in the epidemiology and burden of lung health in Indigenous children and adults. Between 2001 and 2012, the overall mortality of respiratory-related deaths declined, by up to $32 \%$ in adult males, but respiratory disease still accounts for $8 \%$ of the health-gap in mortality between Indigenous and non-Indigenous Australians (18). Infant mortality [respiratory illness is second only to congenital conditions as a cause of death in this age group (19)] has also declined in Australia, but chronic respiratory diseases are being identified increasingly (20). Whether this is related to improved case ascertainment or an increased in prevalence is unknown. In NZ, comparable data are unavailable, but acute admissions (which in children are mainly from respiratory infections) for infectious diseases increased between 1989-93 and 2004-08 from 20.5 to $26.6 \%$ of all hospitalizations (21). This was accompanied by an increasing disparity in the burden of infectious diseases experienced by Māori where the age-standardized rate ratio for hospitalization was 2.15 (95\% CI 2.14-2.16) compared with European and other non-Pacific groups (21).

Currently, in nation-wide data for Indigenous Australians, respiratory disorders are the most common reason for general practice encounters, the second most prevalent self-reported chronic condition and the second most common cause for hospitalization (22). In NZ, mirroring the situation with infectious diseases, respiratory hospitalizations for Māori children are almost twice that for European and other non-Pacific ethnic groups (23). To help reduce the disparity of lung health in Australian and NZ Indigenous children, a partnership involving Indigenous leaders, pediatric and adult clinicians, laboratory scientists, and educationalists was formed in November 2012 under the umbrella of the Centre of Research Excellence (CRE) in Indigenous Children's Lung Health, funded by the National Health of Medical Research Council (Australia). Our overarching aim is to improve the lung health of children, particularly Indigenous children, through research. Here, we describe our framework and key discussions from our second workshop that brought together partners of our CRE, external experts, and higher degree research scholars involved in projects linked with the CRE, whose emblem is displayed in Figure S1 in Supplementary Material.

\section{THE CONCEPTUAL FRAMEWORK FOR DEVELOPING SEVERE BRONCHIECTASIS AND COPD}

Our simplified framework for the development and progression of bronchiectasis and/or COPD in adults is presented in Figure 1. The idea that recurrent acute respiratory infections (ARIs) and subsequent bronchiectasis can be prevented is not new $(24,25)$. In the 1940-50s, astute clinicians described a "pre-bronchiectatic state," which can lead to irreversible lung disease if not well managed (25). They also recognized that persistent or recurrent lower airway infections were associated with developing bronchiectasis (24).

The alveolar stage of human lung development begins at 36-weeks gestation and continues for $\sim 7$ years post-natally (13). Insults in the first few years of life, when post-natal lung development is the most important, are thus likely to have

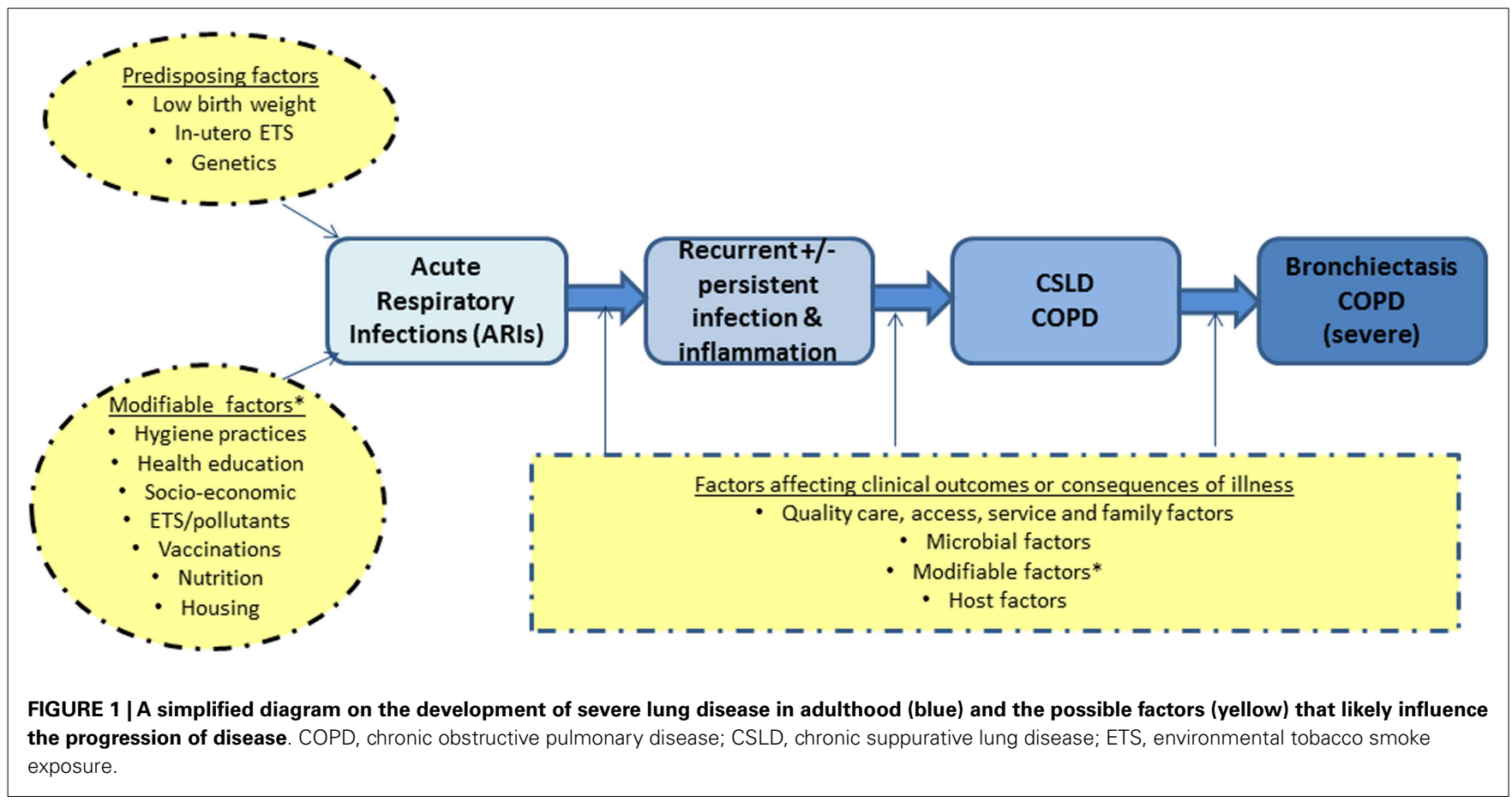


long-term effects. While low birth weight can influence future lung function, there is increasing evidence that early life events (e.g., ARIs) are equally important determinants of adult lung dysfunction, as shown in both animal and human studies (2629). Therefore, interventions that reduce ARIs in Indigenous children would be expected to have both short and potential long-term benefits, especially as severe and recurrent ARIs are independent risk factors for subsequent $\operatorname{COPD}(26,27)$ and bronchiectasis (7).

Chronic suppurative lung disease (CSLD) in children is a specific clinical phenotype involving symptoms and signs of chronic endobronchial purulence accompanied by persistent or recurrent wet cough and airway inflammation, with or without radiographic evidence of bronchiectasis (30). The limitations of radiographic diagnosis, particularly in children $(17,31)$, are recognized. In the Northern Territory (NT, Australia), the incidence of CSLD in the first year of life is 118/100,000; (32) while the national incidence of radiographically confirmed bronchiectasis in the NZ population aged $<15$ years is $3.7 / 100,000$, twice that of cystic fibrosis (33). In Central Australian Aboriginal children (34) and Alaskan Native children (35), CSLD affects one in every 63-68 children $(\sim 1500 / 100,000)$, yet there are few resources directed at prevention, clinical management, and research. Deaths are uncommon in children (36), although in NZ a $2 \%$ mortality rate as a direct result of bronchiectasis was reported from a single tertiary center (37). In contrast, a substantial proportion of Indigenous Australian adults with bronchiectasis die in their fourth decade of life (38).

In adults, the link between COPD and bronchiectasis is increasingly appreciated (39). Those with severe COPD are more likely to have bronchiectasis (40). Furthermore, bronchiectasis in children and adults is often missed or misdiagnosed as asthma $(9,41)$, as chronic cough in the general population is dismissed frequently as unimportant. We found recently that $>20 \%$ of children with chronic cough ( $>4$ weeks duration) had seen a doctor $>20$ times before referral and receiving appropriate treatment (42). Among Indigenous people in Australia, chronic cough is often "normalized," in contrast to non-Indigenous Australians (43).

Based on the above framework, our approach to achieve improvements in lung health relevant to Indigenous child health focuses on intervention points that are feasible in the clinical context. Our CRErelated projects encompass various aspects relevant to CSLD (Figure 1); most are listed online ${ }^{1}$. Here, we highlight key discussions points from our recent workshop.

\section{INDIGENOUS VOICES AND THE PARADIGM OF RESEARCH AND CARE}

The approach within our CRE projects is concurrent health education for child caregivers, using culturally sensitive methods, and participation is informed and supported, leading to very high retention rates in randomized controlled trials (RCTs) (44). Projects are accompanied by knowledge translation plans reviewed and endorsed by an Advisory Board (see text footnote 1). An Indigenous Reference Group (IRG) also provides advice before commencing projects. The IRG remain informed throughout the projects and, on its closure, advises on how to provide feedback ${ }^{2}$.

Our projects have also improved community engagement (45). In NZ, whanau (families) of children with bronchiectasis are a driving force leading to Māori community leaders developing an inaugural website for the purpose of providing education and support for all families with children similarly affected. The children themselves are being encouraged to tell their own stories about their health online. It is hoped that this will be a platform, which will continue to improve awareness and generate increased resourcing for this patient group. However, more can always be done. Indigenous leaders of the group challenged us to take further steps, such as examining the role of traditional healers and medicines in our research, adopting an approach to "take your mob with you," improving the consent process for Indigenous carers, taking into account intergenerational effects and extending our influence beyond lung health. The importance of the work and voices of the four Indigenous higher degree research scholars were highlighted at the workshop.

While a perception remains that Indigenous populations are "over-researched," in reality there are few RCTs relevant to ethnic disparities in clinical outcomes (46). Indeed, major funding bodies (e.g., The National Institutes of Health, USA) now have policies to ensure that minority groups and women are included in all clinical trials (47). Given the relative paucity of strategies for recruiting and retaining Indigenous people in RCTs (48), McCallum and colleagues' study, where $>97 \%$ of Indigenous children were retained in a RCT (44), is a model that should be extended to other studies.

\section{HOST-PATHOGEN INTERACTION IN BRONCHIECTASIS - THE MANY QUESTIONS}

There are many clinical and research gaps relating to the pathogenesis and management of CSLD, including bronchiectasis. This year's scientific component of the workshop focused largely on the interactions between the lower airways microbiome, host defense mechanisms, and clinical factors relevant to children with CSLD/bronchiectasis.

Few studies have addressed the hostpathogen interaction in children with, or at risk of, CSLD. Pizzutto et al (49) found that children with CSLD have an altered systemic cell-mediated immune response to non-typeable Haemophilus influenzae (NTHi) strains in vitro. The peripheral blood mononuclear cells of 80 children with CSLD and 51 controls were stimulated with antigens and mitogens and cytokine responses measured (49). The major finding was that those with CSLD produced significantly less interferon-gamma (IFN- $\gamma$ ) in response to NTHi than healthy controls. This deficient IFN- $\gamma$ response may contribute to increased susceptibility to NTHi infections and to the pathogenesis of CSLD in children. Findings from a larger group of children found that this deficit can be partially corrected by immunization with

\footnotetext{
${ }^{1}$ http://www.menzies.edu.au/page/Research/Centres_initiatives_and_projects/Centre_for_Research_Excellence_Lung_health/

${ }^{2} \mathrm{http}$ ://www.menzies.edu.au/page/About_Us/Board_and_Menzies_committees/Indigenous_Reference_Group/
} 
a licensed pneumococcal-NTHI protein $\mathrm{D}$-conjugate vaccine (50). NTHi is particularly important in CSLD/bronchiectasis (51) and COPD (52) as it is the most common bacteria cultured from the lower airways of children and adults with both diseases.

Whether variants of the genetically diverse NTHi or other pathogens have different virulence strategies in relation to the airway response is unknown. Such data are important for future vaccine development, especially as epidemiologically unrelated NTHi isolates lacking protein $\mathrm{D}$ have been detected in Indigenous population (53). Delineating evolutionary changes within the bacterial genome over time and relating this to differential host responses and disease severity remain elusive. Clinical outcome data associating deficits in T-cell function is another research gap. Further, although relating host responses to a single pathogen is useful for understanding the pathogenesis of CSLD and COPD, this is only a small component of the overall host-pathogen interaction. Increasingly, the complexity of the lower airway pathobiology is being understood, such as the contribution of the airway microbiome, biofilms (54), local innate and adaptive immune responses, the influence of antibiotics upon bacterial communities, and the physiological stresses imposed by the lung microenvironment (55).

Data relating to microbiota in human health and disease are increasing exponentially. However, many challenges remain for respiratory studies, such as specimen types and handling (56), sampling the lower airways in young children, and differentiating cause and effect. Longitudinal cohort studies relating microbiota composition to clinical outcomes and inflammation are needed. The role of host tolerance to members of the microbiota within the respiratory tract is also unknown. The relative clinical significance of core versus satellite microbiota, the interaction of the pulmonary microbiome with respect to invading respiratory viruses and oral and gut microbiota, and the roles of these to the pathogenesis of CSLD/bronchiectasis have yet to be studied. Additionally, the concept of mucosal immunization (57) and/or probiotics (58) protecting against ARIs is intriguing.

\section{OTHER STUDIES AND THE NEED FOR} STUDIES ADDRESSING PREVENTION

Our current work has an increased focus on primary and secondary/tertiary prevention and treatment strategies, as outlined on our CRE website. Examples include earlier detection of disease through improving follow-up of children posthospitalization and improving the treatment for bronchiectasis to prevent or to minimize the progression of lung disease. The importance of the latter was acknowledged by our CRE, particularly with tobacco smoking. Once smoking becomes established, it is difficult to discontinue. If individuals avoid smoking during adolescence, it is unlikely that they will take it up later (59), while in contrast the probability of quitting is inversely proportional to the age of initiation (60). Indeed, a homevisit based RCT, using a culturally sensitive approach undertaken by Indigenous workers in Australia and Māori workers in $\mathrm{NZ}$, was unsuccessful in reducing tobacco smoke exposure of Indigenous children when compared to routine care (61).

\section{SUMMARY}

Addressing health issues in childhood is needed to reduce the long-term impairment and social disadvantage in adults. This paradigm is striking for lung health for many reasons, including the impact of respiratory infections and environmental insults upon post-natal lung development, which increase the risk of future lung disease, such as COPD and bronchiectasis. We have briefly presented our framework for the development of severe COPD and/or bronchiectasis (Figure 1) and our model of research and care. In our second annual workshop, we also highlighted several questions concerning the airway microbiome and related host responses in children with CSLD/bronchiectasis.

Through our CRE, we have built partnerships with Indigenous leaders, scientists, and clinicians working toward a common goal of reducing disparity though high-quality science and care. While we are beginning to improve lung health in Indigenous children through several projects addressing various clinically feasible interventions, much work is still to be done in reducing disparity in lung health between Indigenous and non-Indigenous Australian and NZ peoples.

\section{AUTHOR CONTRIBUTIONS}

AC conceptualized the framework and manuscript, and wrote the first draft. The section on the microbiota and host response was a collection of ideas from the speakers at the workshop. The writing group amended the manuscript and the extended group reviewed it.

\section{ACKNOWLEDGMENTS}

The workshop and this work are supported by a NHMRC Centre for Research Excellence for lung health in Aboriginal and Torres Strait Islanders grant (1040830). Anne B. Chang is supported by a NHMRC practitioner fellowship (1058213). Heidi Smith-Vaughan (1024175) and Kerry-Ann F. O'Grady (1045157) are supported by NHMRC career development fellowships. Maree Toombs (1053961) and Robyn L. Marsh (1034703) are supported by NHMRC early career fellowships. Lucas R. Hoffman is supported by a National Institutes of Health (USA) Independent Scientist Award (K02HL105543).

\section{SUPPLEMENTARY MATERIAL}

The Supplementary Material for this article can be found online at http: //www.frontiersin.org/Journal/10.3389/

fped.2015.00009/full

\section{REFERENCES}

1. King M. An overall approach to health care for indigenous peoples. Pediatr Clin North Am (2009) 56:1239-42. doi:10.1016/j.pcl.2009.09.005

2. Bambra C, Gibson M, Petticrew M, Sowden A, Whitehead M, Wright K. et al. Tackling the Wider Social Determinants of Health and Health Inequalities: Evidence from Systematic Reviews (2009). Available from: http://www.york.ac.uk/ phrc/D2-06\%20Final\%20Report.pdf

3. Walker CL, Rudan I, Liu L, Nair H, Theodoratou E, Bhutta ZA, et al. Global burden of childhood pneumonia and diarrhoea. Lancet (2013) 381:1405-16. doi:10.1016/S0140-6736(13)60222-6

4. Rudan I, Boschi-Pinto C, Biloglav Z, Mulholland K, Campbell H. Epidemiology and etiology of childhood pneumonia. Bull World Health Organ (2008) 86:408-16. doi:10.2471/BLT.07.048769

5. Lamprecht B, McBurnie MA, Vollmer WM, Gudmundsson G, Welte T, Nizankowska-Mogilnicka $\mathrm{E}$, et al. COPD in never smokers: results from the population-based burden of obstructive lung disease study. Chest (2011) 139:752-63. doi:10.1378/ chest.10- 1253

6. Leung JM, Sin DD. COPD in never smokers: prognosis unveiled. Lancet Respir Med (2013) 1:502-4. doi:10.1016/S2213-2600(13)70157-7

7. Valery PC, Torzillo PJ, Mulholland EK, Boyce NC, Purdie DM, Chang AB. A hospital-based case-control study of bronchiectasis in Indigenous children in central Australia. Pediatr 
Infect Dis J (2004) 23:902-8. doi:10.1097/01.inf. 0000142508.33623.2f

8. Chang AB, Grimwood K, Macguire G, King PT, Morris PS, Torzillo PJ. Management of bronchiectasis and chronic suppurative lung disease (CSLD) in Indigenous children and adults from rural and remote Australian communities. Med JAust (2008) 189:386-93.

9. Gupta S, Siddiqui S, Haldar P, Raj JV, Entwisle JJ, Wardlaw AJ, et al. Qualitative analysis of high resolution computed tomography scans in severe asthma. Chest (2009) 136:1521-8. doi:10.1378/ chest.09-0174

10. Chang AB. Specialty grand challenge - pediatric pulmonology. Front Pediatr (2013) 1:14. doi:10. 3389/fped.2013.00014

11. Campbell F, Conti G, Heckman JJ, Moon SH, Pinto R, Pungello E, et al. Early childhood investments substantially boost adult health. Science (2014) 343:1478-85. doi:10.1126/science. 1248429

12. Aizer A, Currie J. The intergenerational transmission of inequality: maternal disadvantage and health at birth. Science (2014) 344:856-61. doi:10. $1126 /$ science. 1251872

13. Shi W, Bellusci S, Warburton D. Lung development and adult lung diseases. Chest (2007) 132:651-6. doi:10.1378/chest.06-2663

14. Thapar A, Harold G, Rice F, Ge X, Boivin J, Hay $D$, et al. Do intrauterine or genetic influences explain the foetal origins of chronic disease? A novel experimental method for disentangling effects. BMC Med Res Methodol (2007) 7:25. doi:10.1186/1471-2288-7-25

15. Stocks J, Hislop A, Sonnappa S. Early lung development: lifelong effect on respiratory health and disease. Lancet Respir Med (2013) 1:728-42. doi: 10.1016/S2213-2600(13)70118-8

16. Bush A. COPD: a pediatric disease. COPD (2008) 5:53-67. doi:10.1080/15412550701815965

17. Chang AB, Byrnes CA, Everard ML. Diagnosing and preventing chronic suppurative lung disease (CSLD) and bronchiectasis. Paediatr Respir Rev (2011) 12:97-103. doi:10.1016/j.prrv.2010.10.008

18. Australian Institute of Health and Welfare. Mortality and Life Expectancy of Indigenous Australians: 2008 to 2012 (Cat. No. IHW 140). Canberra, ACT: AIHW (2014).

19. Yang IA, Fong KM, Zimmerman PV, Holgate ST, Holloway JW. Genetic susceptibility to the respiratory effects of air pollution. Thorax (2008) 63:555-63. doi:10.1136/thx.2007.079426

20. O'Grady KA, Revell A, Maguire GP, Millonig R, Newman MA, Reid DW, et al. Lung health care for Aboriginal and Torres Strait Islander Queenslanders: breathing easy is not so easy. Aust Health Rev (2011) 35:512-9. doi:10.1071/AH10973

21. Baker MG, Barnard LT, Kvalsvig A, Verrall A, Zhang J, Keall M, et al. Increasing incidence of serious infectious diseases and inequalities in New Zealand: a national epidemiological study. Lancet (2012) 379:1112-9. doi:10.1016/S0140-6736(11) 61780-7

22. Australian Institute of Health and Welfare. The Health and Welfare of Australia's Aboriginal and Torres Strait Islander People: An Overview 2011 (Cat. No. IHW 42). Canberra, ACT: AIHW (2011).

23. Craig E, Dell R, Reddington A, Adams J, Oben G, Wicken A, et al. Te Ohonga Ake The Determinants of Health for Mâori Children and Young People in New Zealand. New Zealand Child and Youth Epidemiology Service. (2014). Available from: http:// www.health.govt.nz/publication/te-ohonga-akedeterminants-health-maori-children-and-youngpeople

24. Finke W. Prospects for prevention of chronic bronchitis and bronchiectasis; rational management of bronchopulmonary infections by penicillin aerosol therapy. J Pediatr (1948) 33:29-42. doi:10.1016/ S0022-3476(48)80150-2

25. Field CE. Bronchiectasis in childhood: II. Aetiology and pathogenesis, including a survey of 272 cases of doubtful irreversible bronchiectasis. Pediatrics (1949) 4:231-48.

26. Dharmage SC, Erbas B, Jarvis D, Wjst M, Raherison C, Norbäck D, et al. Do childhood respiratory infections continue to influence adult respiratory morbidity? Eur Respir J (2009) 33:237-44. doi:10.1183/09031936.00062907

27. Tennant PW, Gibson GJ, Parker L, Pearce MS. Childhood respiratory illness and lung function at ages 14 and 50 years. Chest (2010) 137:146-55. doi:10.1378/chest.09-0352

28. Maritz G, Probyn M, De MR, Snibson K, Harding R. Lung parenchyma at maturity is influenced by postnatal growth but not by moderate preterm birth in sheep. Neonatology (2008) 93:28-35. doi:10.1159/000105522

29. Snibson K, Harding R. Postnatal growth rate, but not mild preterm birth, influences airway structure in adult sheep challenged with house dust mite. Exp Lung Res (2008) 34:69-84. doi:10.1080/ 01902140701807720

30. Chang AB, Bell SC, Byrnes CA, Grimwood K, Holmes PW, King PT, et al. Bronchiectasis and chronic suppurative lung disease (CSLD) in children and adults in Australian and New Zealand: Thoracic Society of Australia and New Zealand and Australian Lung Foundation Position Statement. Med J Aust (2010) 193:356-65.

31. Kapur N, Masel JP, Watson D, Masters IB, Chang AB. Bronchoarterial ratio on high resolution CT scan of the chest in children without pulmonary pathology: need to redefine bronchial dilatation. Chest (2011) 139:1445-50. doi:10.1378/chest.101763

32. O’Grady KA, Torzillo PJ, Chang AB. Hospitalisation of Indigenous children in the northern territory for lower respiratory illness in the first year of life. Med J Aust (2010) 192:586-90.

33. Twiss J, Metcalfe R, Edwards EA, Byrnes C. New Zealand national incidence of bronchiectasis "too high" for a developed country. Arch Dis Child (2005) 90:737-40. doi:10.1136/adc.2004.066472

34. Chang AB, Masel JP, Boyce NC, Wheaton G, Torzillo PJ. Non-CF bronchiectasis-clinical and HRCT evaluation. Pediatr Pulmonol (2003) 35:477-83. doi:10.1002/ppul.10289

35. Singleton R, Morris A, Redding G, Poll J Holck P, Martinez P, et al. Bronchiectasis in Alaska native children: causes and clinical courses. Pediatr Pulmonol (2000) 29:182-7. doi:10.1002/(SICI)1099-0496(200003)29:3<182: :AID-PPUL5>3.3.CO;2-K

36. Roberts HJ, Hubbard R. Trends in bronchiectasis mortality in England and Wales. Respir Med (2010) 104:981-5. doi:10.1016/j.rmed.2010.02.022
37. Munro KA, Reed PW, Joyce H, Perry D, Twiss J, Byrnes CA, et al. Do New Zealand children with non-cystic fibrosis bronchiectasis show disease progression? Pediatr Pulmonol (2011) 46:131-8. doi:10.1002/ppul.21331

38. Steinfort DP, Brady S, Weisinger HS, Einsiedel L. Bronchiectasis in central Australia: a young face to an old disease. Respir Med (2008) 102:574-8. doi:10.1016/j.rmed.2007.11.007

39. Bilton D. Update on non-cystic fibrosis bronchiectasis. Curr Opin Pulm Med (2008) 14:595-9. doi: 10.1097/MCP.0b013e328312ed8c

40. Martínez-García MÁ, Soler-Cataluña JJ, Donat Sanz Y, Catalán Serra P, Agramunt Lerma M, Ballestín Vicente J, et al. Factors associated with bronchiectasis in patients with COPD. Chest (2011) 140:1130-7. doi:10.1378/chest.10-1758

41. Donnelly DE, Critchlow A, Everard ML. Outcomes in children treated for persistent bacterial bronchitis. Thorax (2007) 62:80-4. doi:10.1136/thx.2006. 058933

42. Marchant JM, Newcombe PA, Juniper EF, Sheffield $\mathrm{JK}$, Stathis SL, Chang AB. What is the burden of chronic cough for families? Chest (2008) 134:303-9. doi:10.1378/chest.07-2236

43. Morey MJ, Cheng AC, McCallum GB, Chang AB. Accuracy of cough reporting by carers of Indigenous children. J Paediatr Child Health (2013) 49:E199-203. doi:10.1111/jpc.12118

44. McCallum GB, Versteegh LA, Morris PS, McKay CC, Jacobsen NJ, White AV, et al. Mobile phones support adherence and retention of indigenous participants in a randomised controlled trial: strategies and lessons learnt. BMC Public Health (2014) 14:622. doi:10.1186/1471-2458-14-622

45. Medlin LG, Chang AB, Fong K, Jackson R, Bishop P, Dent $A$, et al. Indigenous respiratory outreach care: the first 18 months of a specialist respiratory outreach service to rural and remote Indigenous communities in Queensland, Australia. Aust Health Rev (2014) 38:447-53. doi:10.1071/AH13136

46. Radhakrishna N, Hew M. Addressing ethnic disparity in asthma trials. Respirology (2014) 19:775-6. doi:10.1111/resp.12338

47. Available from: http://orwh.od.nih.gov/research/ inclusion/background.asp

48. Glover M, Kira A, Johnston V, Walker N, Thomas $\mathrm{D}$, Chang $\mathrm{AB}$, et al. A systematic review of barriers and facilitators to participation in randomized controlled trials by Indigenous people from New Zealand, Australia, Canada and the United States. Glob Health Promot (2014). doi:10.1177/ 1757975914528961

49. Pizzutto SJ, Yerkovich ST, Upham JW, Hales BJ, Thomas WR, Chang AB. Children with chronic suppurative lung disease have a reduced capacity to synthesize interferon-gamma in vitro in response to non-typeable Haemophilus influenzae. PLoS One (2014) 9:e104236. doi:10.1371/journal. pone.0104236

50. Pizzutto SJ, Yerkovich ST, Upham JW, Hales BJ, Thomas WR, Chang AB. Improving immunity to Haemophilus influenzae in children with chronic suppurative lung disease. Vaccine (2015) 33:321-6. doi:10.1016/j.vaccine.2014.11.024

51. Hare KM, Binks MJ, Grimwood K, Chang AB, Leach AJ, Smith-Vaughan H. Culture and PCR detection of Haemophilus influenzae 
and Haemophilus haemolyticus in Australian Indigenous children with bronchiectasis. J Clin Microbiol (2012) 50:2444-5. doi:10.1128/JCM. 00566- 12

52. King PT, Lim S, Pick A, Ngui J, Prodanovic Z, Downey W, et al. Lung T-cell responses to nontypeable Haemophilus influenzae in patients with chronic obstructive pulmonary disease. J Allergy Clin Immunol (2013) 131:1314-21. doi:10.1016/j. jaci.2012.09.030

53. Smith-Vaughan HC, Chang AB, Sarovich DS, Marsh RL, Grimwood K, Leach AJ, et al. Absence of an important vaccine and diagnostic target in carriage- and disease-related nontypeable Haemophilus influenzae. Clin Vaccine Immunol (2014) 21:250-2. doi:10.1128/CVI. 00632-13

54. Marsh RL, Thornton RB, Smith-Vaughan HC, Richmond P, Pizzutto SJ, Chang AB. Identification of biofilm in bronchoalveolar lavage from children with bronchiectasis without Pseudomonas aeruginosa infection. Pediatr Pulmonol (2014). doi:10. 1002/ppul.23031

55. Rogers GB, Hoffman LR, Carroll MP, Bruce KD. Interpreting infective microbiota: the importance of an ecological perspective. Trends Microbiol (2013) 21:271-6. doi:10.1016/j.tim.2013.03. 004

56. Rogers GB, Shaw D, Marsh RL, Carroll MP, Serisier DJ, Bruce KD. Respiratory microbiota: addressing clinical questions, informing clinical practice. Thorax (2015) 70:74-81. doi:10.1136/ thoraxjnl-2014-205826

57. Foxwell AR, Kyd JM, Cripps AW. Programmed inflammatory processes induced by mucosal immunisation. Vaccine (2001) 19:2522-6. doi:10. 1016/S0264-410X(00)00483-7

58. West NP, Horn PL, Pyne DB, Gebski VJ, Lahtinen SJ, Fricker PA, et al. Probiotic supplementation for respiratory and gastrointestinal illness symptoms in healthy physically active individuals. Clin Nutr (2014) 33:581-7. doi:10.1016/j.clnu.2013.10.002

59. Mayhew KP, Flay BR, Mott JA. Stages in the development of adolescent smoking. Drug Alcohol Depend (2000) 59(Suppl 1):S61-81. doi:10.1016/ S0376-8716(99)00165-9

60. Breslau N, Peterson EL. Smoking cessation in young adults: age at initiation of cigarette smoking and other suspected influences. Am J Public Health (1996) 86:214-20. doi:10.2105/AJPH.86.2.214

61. Walker N, Johnston V, Glover M, Bullen C, Trenholme A, Chang A, et al. Effect of a family-centered, secondhand smoke intervention to reduce respiratory illness in indigenous infants in Australia and New Zealand: a randomized controlled trial. Nicotine Tob Res (2015) 17:48-57. doi:10.1093/ntr/ ntu 128

Conflict of Interest Statement: Anne B. Chang has received funding from GlaxoSmithKline for an investigator driven study on the effects of Synflorix ${ }^{\circledR}$ on airway bacteriology. Keith Grimwood has participated on advisory boards to GlaxoSmithKline on pneumococcal conjugate vaccines. All other authors have no conflicts of interest to declare.

Received: 31 October 2014; paper pending published: 21 December 2014; accepted: 26 January 2015; published online: 13 February 2015.

Citation: Chang AB, Marsh RL, Upham JW, Hoffman LR, Smith-Vaughan H, Holt D, Toombs M, Byrnes C, Yerkovich ST, Torzillo PJ, O'Grady K-AF and Grimwood $K$ (2015) Toward making inroads in reducing the disparity of lung health in Australian Indigenous and New Zealand Māori children. Front. Pediatr. 3:9. doi:10.3389/fped.2015.00009

This article was submitted to Pediatric Pulmonology, a section of the journal Frontiers in Pediatrics.

Copyright (C) 2015 Chang, Marsh, Upham, Hoffman, Smith-Vaughan, Holt, Toombs, Byrnes, Yerkovich, Torzillo, O'Grady and Grimwood. This is an open-access article distributed under the terms of the Creative Commons Attribution License (CC BY). The use, distribution or reproduction in other forums is permitted, provided the original author(s) or licensor are credited and that the original publication in this journal is cited, in accordance with accepted academic practice. No use, distribution or reproduction is permitted which does not comply with these terms. 